\title{
Differential Effects of Recombinant Human EGF on Proliferation and Radiation Survival of Normal Fibroblast and Cancer Cell Lines
}

\author{
Eun-Kyung Kwon ${ }^{1,2,4}$, Seung-Hee Lee ${ }^{1,2}$, Kyubo Kim $^{1}$, Hong-Gyun Wu ${ }^{*, 1,4}$ and Sang-wook Lee ${ }^{5}$ \\ ${ }^{I}$ Department of Radiation Oncology, Seoul National University College of Medicine, Seoul, Republic of Korea \\ ${ }^{2}$ Cancer Research Institute, Seoul National University College of Medicine, Seoul, Republic of Korea \\ ${ }^{3}$ Institute of Radiation Medicine, Medical Research Center, Seoul National University, Seoul, Republic of Korea \\ ${ }^{4}$ Radiation Applied Life Science Interdisciplinary Course, Seoul National University Graduate School, Seoul, Republic \\ of Korea \\ ${ }^{5}$ Department of Radiation Oncology, University of Ulsan, College of Medicine, Asan Medical Center, Seoul, Republic of \\ Korea
}

\begin{abstract}
Objective: To evaluate the effects of recombinant human epidermal growth factor (rhEGF) on proliferation and radiation survival of normal fibroblast and cancer cell lines both in vitro and in vivo.

Methods: Using normal fibroblast and cancer cell lines, we evaluated the expression of EGFR, and determined their proliferation and survival with rhEGF alone or in combination with radiation. For the combination treatments, we applied 10 nM rhEGF and delivered single radiation doses of $0,2,5$, and $10 \mathrm{~Gy}$. In the animal study, we introduced EMT- 6 cells into $\mathrm{BALB} / \mathrm{c}$ mice to assay for tumor growth delay. We applied single radiation dose of 10 or $20 \mathrm{~Gy}$, with or without 1.0 $\mathrm{mg} / \mathrm{Kg}$ of rhEGF, three times a day, for 7 days.

Results: In a dose-dependent manner, rhEGF stimulated proliferation of the normal fibroblast, but not the cancer cell lines with low or intermediate expression of EGFR. rhEGF inhibited proliferation of the cancer cell line with the highest EGFR expression. Administration of rhEGF in combination with radiation attenuated the cell killing effect of radiation in normal fibroblast, but it had no effect or even augmented the radiation effect in cancer cell lines. In the animal study, we observed no difference in tumor growth rates when rhEGF was combined with radiation compared to radiation alone.
\end{abstract}

Conclusions: Our results suggested that rhEGF might be useful in preventing and/or treating radiation-induced injury without stimulating tumor growth.

Mini-Abstract: rhEGF effectively stimulated proliferation and radiation recovery in normal fibroblasts without promoting the growth of tumor cells. Therefore, it might be useful in preventing and/or treating radiation-induced tissue injury.

Keywords: Recombinant human epidermal growth factor, radiotherapy, in vitro study, in vivo study.

Presented at the $49^{\text {th }}$ Annual Meeting of the American Society for Therapeutic Radiology and Oncology, Oct 28-Nov 1, 2007, Los Angeles, CA.

\section{INTRODUCTION}

Radiation-induced mucosal injury is a common sideeffect observed during and after local irradiation of the head and neck and gastrointestinal tract, and it can mediate doselimiting toxicity that hinders treatment progress. Until recently, no specific method was available to prevent or treat radiation-induced injuries. Besides conservative and/or supportive management for these injuries, the recovery of radiation-induced tissue injury with growth factors or cytokines is under investigation [1-8].

The US Food and Drug Administration has recently approved Palifermin, a recombinant human keratinocyte

*Address correspondence to this author at the Department of Radiation Oncology, Seoul National University College of Medicine, 101 Daehangno, Jongno-gu, Seoul 110-774, Republic of Korea; Tel: +82-2-2072-3177;

Fax: +82-2-765-3317; E-mail: wuhg @ snu.ac.kr growth factor [8], for preventing severe oral mucositis in hematologic malignancy patients receiving myelotoxic therapies and hematopoietic stem cell transplantation. Application of Palifermin for radiation-induced oral mucositis in solid tumors has not been approved yet, although clinical trials are under way. Recently, two animal models were developed for the elucidation of the role of epidermal growth factor (EGF) in the treatment of radiation-induced oral and gastrointestinal mucositis, and recombinant human EGF (rhEGF) was shown to be effective for the recovery of radiation-induced mucosal damage $[9,10]$.

EGF, which is produced by platelets, macrophages, and monocytes, interacts with EGFR on epidermal cells and fibroblasts [11]. Besides stimulating epithelial proliferation, EGF induces a variety of responses, including modification of migration and differentiation processes within epithelial cells [12-14]. EGF also plays a major role in stimulating fibroblasts during the early phases of wound healing $[15,16]$. 
Several other studies have reported that EGF and other growth factors exerted beneficial effects in normal fibroblasts $[11,17,18]$. However, little is known about the effect of EGF on the proliferation of tumor cells and on the survival of irradiated tumor cells. Since EGF and EGFR play an important role in the development and growth of some tumors [16], we designed this study to evaluate the effect of rhEGF on proliferation and radiation survival of cancer cell lines and normal fibroblasts, both in vitro and in vivo.

\section{MATERIALS AND METHODOLOGY}

\section{Study Drug}

rhEGF used in this study was provided by Daewoong Parmaceutical Co. Ltd. (Seoul, Korea). This product is commercially available and indicated for diabetic foot in Korea.

\section{Cell Lines}

To compare expression level of EGF receptor (EGFR), various cancer cell lines were used. NCI-H460, NCI-H1299, A549 (human lung carcinoma), HeLa (human cervical adenocarcinoma), and EMT-6 (mouse mammary sarcoma) were purchased from the American Type Culture Collection (ATCC). AMC-HN9 and AMC-HN3 (human head and neck cancer cell lines) were generous gifts from Prof. Sang-wook Lee at University of Ulsan, Seoul, Korea. Normal primary human cervix fibroblasts and F65 human skin fibroblasts were also used, and these were kind gifts from Prof. YongSang Song at Seoul National University, Seoul, Korea and Prof. Joon Kim at Korea University, Seoul, Korea, respectively.

Cells were maintained at $37{ }^{\circ} \mathrm{C}$ and $5 \% \mathrm{CO}_{2}$ and cultured in RPMI 1640 (Gibco BRL; Gaithersburg, MD, USA), DMEM (Gibco BRL; 31600 034, Grand Island, NY, USA), or MEM (Gibco BRL). All media were supplemented with 10-20\% FBS (Sigma; St. Louis, MO, USA). Serum-free media $(0.05 \%$ FBS $)$ were also used in order to exclude the effects of other growth factors in the FBS.

\section{Clonogenic Assay: rhEGF Alone}

Mid-log phase cells from monolayer cultures were trypsinized and plated in six-well culture plates at cell densities that were optimized for the experimental conditions indicated: $2 \times 10^{2}$ cells were plated for AMC-HN3 cells, and 1 $\mathrm{x} 10^{2}$ cells for other cell lines according to treatment conditions. The cells were then incubated for 24 hours prior to treatment. To measure the effect of rhEGF, $0,0.01,0.1,1$, 10,100 , and $1000 \mathrm{nM}$ rhEGF were added to the medium. Cells were incubated for additional 10 days at $37{ }^{\circ} \mathrm{C}$ without changing the medium, resulting in the formation of colonies. The cells were then fixed with $100 \%$ methanol and stained with $0.5 \%$ crystal violet in methanol. The numbers of colonies (defined as more than 50 cells) were counted. Surviving fraction (SF) was defined as the ratio of the numbers of colonies to the numbers of initially plated cells corrected by plating efficiency (PE), where PE was SF of untreated cells. Each experiment was independently repeated three times.

\section{Clonogenic Assay: Combination of rhEGF and Radiation}

In the experiments using radiation with or without rhEGF, $1 \times 10^{2}$ cells were plated for dose of $2 \mathrm{~Gy}, 3 \times 10^{2}$ cells for $5 \mathrm{~Gy}$, and $1 \times 10^{3}$ cells for $10 \mathrm{~Gy}$, for all cell lines. The cells were then incubated for 24 hours prior to treatment. To compare the combined effect of rhEGF and radiation with the effect of radiation alone, cells were irradiated with 4 MV X-rays generated by a linear accelerator (Clinac 4/100; Varian; Palo Alto, CA), at a dose rate of $2.46 \mathrm{~Gy} / \mathrm{min}$. Where indicated, rhEGF was added to the media at the concentration of $10 \mathrm{nM}$ for 24 hours, after which cells were irradiated in the presence of rhEGF. After 24 hours, the medium was removed, and cells were incubated in drug-free media for 10 days to form colonies. Each experiment was independently repeated three times.

\section{Western Blot Analysis}

Cells were harvested using cold lysis buffer (iNtRON Biotechnology; Seoul, Korea). The lysates were sonicated, clarified by centrifugation at 13,000 rpm for 20 minutes at 4 ${ }^{\circ} \mathrm{C}$, and the supernatants were utilized for analysis. Protein concentrations of the samples were determined with a BCA protein assay kit (PIERCE; Rockford, IL, USA.). The protein was mixed with $5 \mathrm{X}$ sample buffer (2\% SDS, 5\% $\beta$ mercaptoethanol, $20 \%$ glycerol, $0.001 \%$ bromophenol-blue, $0.1 \mathrm{M}$ Tris- $\mathrm{HCl}, \mathrm{pH}$ 6.8) and boiled for 10 minutes. Equal amounts of protein were separated by $6-8 \%$ SDS-PAGE and transferred to PVDF membranes (Millipore Corp; Bedford, MA, USA). Membranes were blocked for 1 hour at room temperature with TBST (10 nM Tris- $\mathrm{HCl}$ [pH 7.5], $150 \mathrm{mM}$ $\mathrm{NaCl}, 0.1 \%$ Tween 20 ) containing 5\% dry milk, and then washed three times with TBST. Membranes were probed at $4{ }^{\circ} \mathrm{C}$ overnight with polyclonal rabbit anti-EGFR (Cell Signaling Technology; Beverly, MA, USA), polyclonal rabbit anti-PCNA (Sigma), polyclonal rabbit anti-Ki67 $\left(\right.$ abcam $^{\circledR}$; Cambridge, UK), at respective dilutions of 1:500, $1: 10000$, and 1:250. The blots were then incubated with peroxidase-conjugated goat anti-rabbit $\operatorname{IgG}$ (Jackson ImmunoResearch Laboratories; West Grove, PA, USA) at a 1:2,000 dilution for 2 hours at room temperature and washed three times with TBST. As a loading control, the same membranes were stripped and probed with monoclonal anti$\alpha$-tubulin (Sigma) at a 1:3,000 dilution at $4{ }^{\circ} \mathrm{C}$ overnight, followed by an incubation with the goat anti-mouse IgG used above at a 1:3,000 dilution for 1 hour at room temperature and three washes with TBST. Immunoreactive proteins were visualized with WEST-ONE TM chemiluminescent substrate (iNtRON Biotechnology) and signals were detected with LAS-3000 (FujiFilm, Tokyo, JAPAN).

\section{Mice and Housing}

All animal experiments were approved by the Institutional Animal Care and Use Committee (IACUC), and performed at the Clinical Research Institute, Seoul National University Hospital, Seoul, Korea (an AAALAC accredited facility). National Research Council (NRC) guidelines for the care and use of laboratory animals were observed at all times. The mice were bred and housed under pathogen-free conditions with controlled humidity $(30 \%-50 \%)$ and temperature $\left(21-24{ }^{\circ} \mathrm{C}\right)$. A light program regulated a 12/12-h light dark-rhythm, with lights on from 8 a.m. to 8 p.m. The mice were kept in Macrolon ${ }^{\circledR}$ cages on sawdust bedding (Sniff 3/4; Altrogge; Lage, Germany). Standard mouse diet (Altromin 1326; Altrogge) and filtered city tap water from standard Perspex drinking bottles were provided ad libitum. 
Male Balb/c mice (6 weeks old; 25-30 g) were implanted with an EGFR-positive mouse breast sarcoma cell line (EMT-6), as described below.

\section{Mouse Tumor Models and Measurement of Tumor Growth Delay}

Animals were injected subcutaneously in the right thigh with $1 \times 10^{6}$ tumor cells in a saline suspension volume of 50 $\mu 1$. One tumor per animal was implanted. Mice with an average tumor volume of $200-300 \mathrm{~mm}^{3}$ were grouped as follows: Vehicle only $=$ vehicle $(100 \mu \mathrm{l})$ for 7 consecutive days, three times a day; "Vehicle+RT(10Gy)" = irradiation with $10 \mathrm{~Gy}$ followed by vehicle $(100 \mu 1)$ for 7 consecutive days, three times a day; "Vehicle+RT(20Gy)" = irradiation with $20 \mathrm{~Gy}$, followed by vehicle $(100 \mu$ l) for 7 consecutive days, three times a day; EGF only = rhEGF $1.0 \mathrm{mg} / \mathrm{kg}$ for 7 consecutive days, three times a day; "EGF+RT(10Gy)" = irradiation with $10 \mathrm{~Gy}$, followed by rhEGF $(1.0 \mathrm{mg} / \mathrm{kg})$ for 7 consecutive days, three times a day; "EGF+RT(20Gy)" = irradiation with 20 Gy followed by rhEGF $(1.0 \mathrm{mg} / \mathrm{kg})$ for 7 consecutive days, three times a day. rhEGF and vehicle was given intraperitoneally at $8 \mathrm{am}, 1 \mathrm{pm}$, and before RT.

Each group consisted of five to seven animals. Mice were irradiated in a custom-maid mouse thigh jig with $4 \mathrm{MV}$ Xrays generated by a linear accelerator (Clinac 4/100) at a dose rate of $250 \mathrm{MU} / \mathrm{min}$. Length and width of the tumors (in $\mathrm{mm}$ ) were measured with digital calipers three times a week by two independent researchers (KEK and LSH) for 21 days after irradiation, or until the tumor volume reached five times $(5 x)$ the original pretreatment volume. These measurement was performed by researcher unaware of treatments. Tumor volume $\left(\mathrm{mm}^{3}\right)$ was calculated according to the following formula: tumor volume $=1 / 2 \mathrm{x}$ length $\mathrm{x}$ width $\mathrm{x}$ width. The data are expressed as the relative tumor volume \pm standard deviation (SD), which is the ratio of the tumor volume measured each day to the pretreatment volume in each experimental condition. Experiments were independently repeated three times.

\section{Statistical Analysis}

All values are presented as means \pm standard deviation (SD), and $n$ indicates the number of observations (in vitro) or the number of animals in the treatment group (in vivo). In vivo, the relative differences in tumor growth in EMT-6implanted mice treated with rhEGF only, irradiation only, or both were analyzed by analysis of variance and expressed as $p$ values. A $p$ value of less than 0.05 was considered to be significant. Three independent experiments performed on different days were used for statistical analysis.

\section{RESULTS}

\section{Expression of EGFR in Normal Fibroblasts and Cancer Cell Lines}

To figure out difference in functional consequences according to the expression level of EGFR, western blot analysis was performed for various cell lines including NCI-H460, NCI-H1299, A549, HeLa, EMT-6, AMC-HN9, AMC-HN3, human cervix fibroblasts, and F65 human skin fibroblasts. We confirmed different level of EGFR protein expression among these cell lines (Fig. 1). For subsequent experiments, we selected three cancer cell lines with different expression level of EGFR: highly expressed, AMC-HN3; intermediate, A549; lowly expressed, EMT-6, respectively.

We repeated the proliferation experiments using another rhEGF purchased from R\&D Systems Inc. (Minneapolis, MN, USA) and confirmed that there was no difference in rhEGF effects according to the manufacturers (data not shown).

\section{Effect of rhEGF on Proliferation in Normal Fibro- blasts and Cancer Cell Lines}

Three cancer cell lines, AMC-HN3, A549, and EMT-6, were cultured with varying concentrations of rhEGF $(0.01$ $1000 \mathrm{nM}$ ) for five days, and clonogenic assays were performed. For AMC-HN3 cell lines, the number of colonies was decreased in a dose-dependent manner. The number of colonies of A549 and EMT-6 cell lines was also decreased by the concentrations above $0.1 \mathrm{nM}$ (Fig. 2) and we observed similar effects under serum-free conditions (data not shown).

We treated primary human fibroblasts cultured from a normal uterine cervix sample with various concentrations of rhEGF, ranging from 0.01 to $1000 \mathrm{nM}$. rhEGF treatment increased the number of colonies (Fig. 2). We also observed similar effects under serum-free conditions (data not shown).

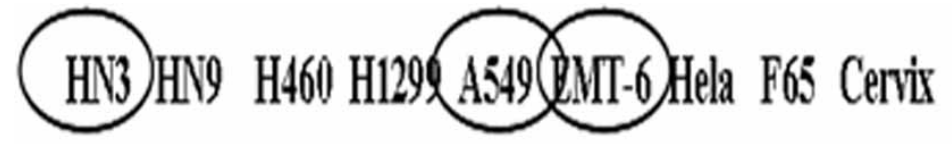

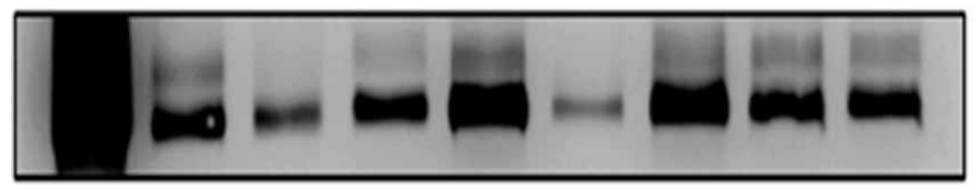

EGFR
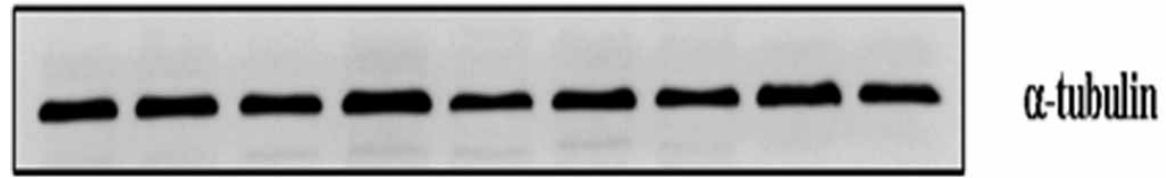

Fig. (1). Expression of epidermal growth factor receptor in various cancer cell lines and normal fibroblasts. 
$\mathbf{a}$

AMC-HN3

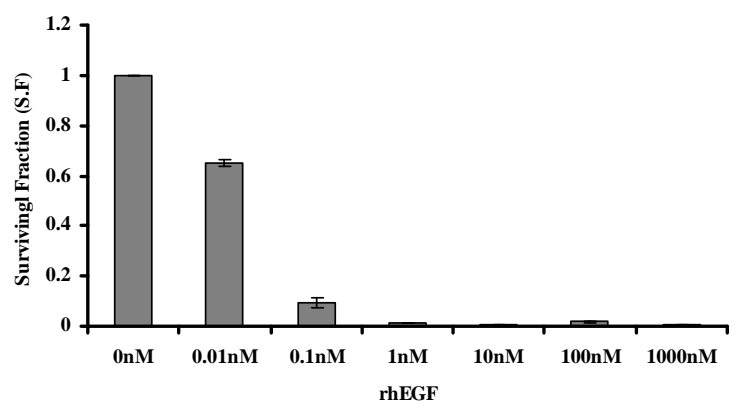

c

EMT-6

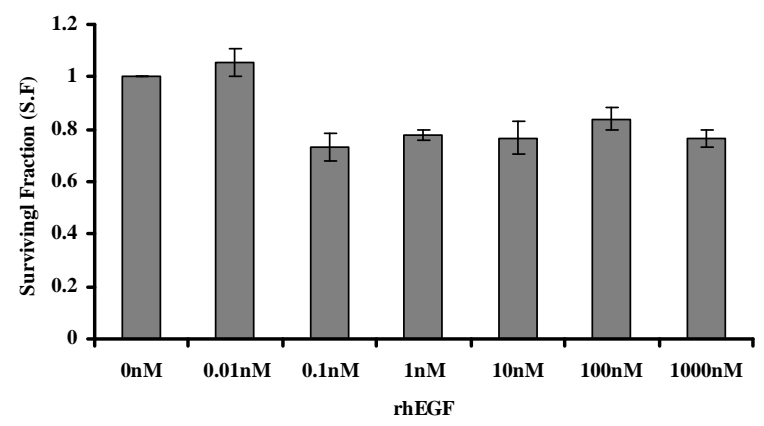

b

A549

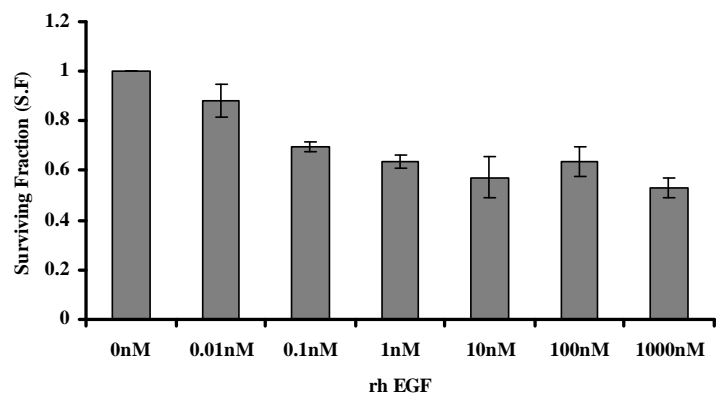

d

Fig. (2). Results of clonogenic assays of rhEGF-treated cells.

(a) AMC-HN3, (b) A549, (c) EMT-6, (d) normal cervix fibroblast.

The cells were incubated for 24 hours prior to treatment with $0,0.01,0.1,1,10,100$, or $1000 \mathrm{nM}$ rhEGF. After 10 days of incubation at $37{ }^{\circ} \mathrm{C}$, colonies were counted. In the AMC-HN3 cells, the number of colonies decreased as the rhEGF concentration increased. In contrast, rhEGF increased the number of colonies formed from normal fibroblasts.

\section{The Effect of rhEGF on Cell Killing by Ionizing Radiation}

We subjected our three cancer cell lines and normal fibroblasts to ionizing radiation, followed by a ten-day culture with unsupplemented medium or medium containing $10 \mathrm{nM}$ of rhEGF. In the clonogenic assays, we observed that rhEGF had a radio-sensitizing effect on AMC-HN3 cells, but it had no significant effect in A549 and EMT-6 cell lines. In normal fibroblasts, rhEGF inhibited the cell killing effect of radiation (Fig. 3).

\section{Changes in Expression Levels of PCNA and Ki-67 in Normal Fibroblasts and Cancer Cell Lines Treated with rhEGF}

After culturing serum-starved cells with $10 \mathrm{nM}$ rhEGF for varying time periods $(5 \mathrm{~min}, 4 \mathrm{hr}, 24 \mathrm{hr}, 48 \mathrm{hr}$, and 72 hr), we measured expression levels of two proliferationassociated proteins, PCNA and Ki67, using immunoblotting. We detected both proteins in all cell lines, even under control (no rhEGF) conditions. Treatment with rhEGF significantly decreased Ki67 levels in all three cancer cell lines (AMCHN3, A549, and EMT-6). Ki67 was hardly expressed in three cancer cell lines at $72 \mathrm{hr}$. In contrast, rhEGF substantially enhanced Ki67 expression in normal fibroblasts (Fig. 4).

\section{Effect of rhEGF on Tumor Growth Delay of Ionizing Radiation in Animal Tumor Model}

To ascertain whether rhEGF effects in vitro translated into tumor growth delay in vivo, we implanted Balb/c mice with EMT-6 cancer cells via subcutaneous injection and monitored tumor volumes following radiotherapy, rhEGF treatment, or both. After 21 days, the relative tumor volume was 8.0 in the control (vehicle only) group (Fig. 5). A single radiation dose of $10 \mathrm{~Gy}$ or $20 \mathrm{~Gy}$ significantly delayed tumor growth; relative tumor volumes were $4.6(\mathrm{p}<0.001)$ and 3.0 $(\mathrm{p}<0.001) \mathrm{mm}^{3}$, in these respective groups. Interestingly, rhEGF treatment alone also delayed tumor growth; this group displayed a relative tumor volume of $6.0(\mathrm{p}<0.001)$. Relative tumor volumes between the group that received radiation plus rhEGF and the group that received radiation alone were not statistically different. Importantly, these results verify that rhEGF did not stimulate tumor growth under these conditions. 
a

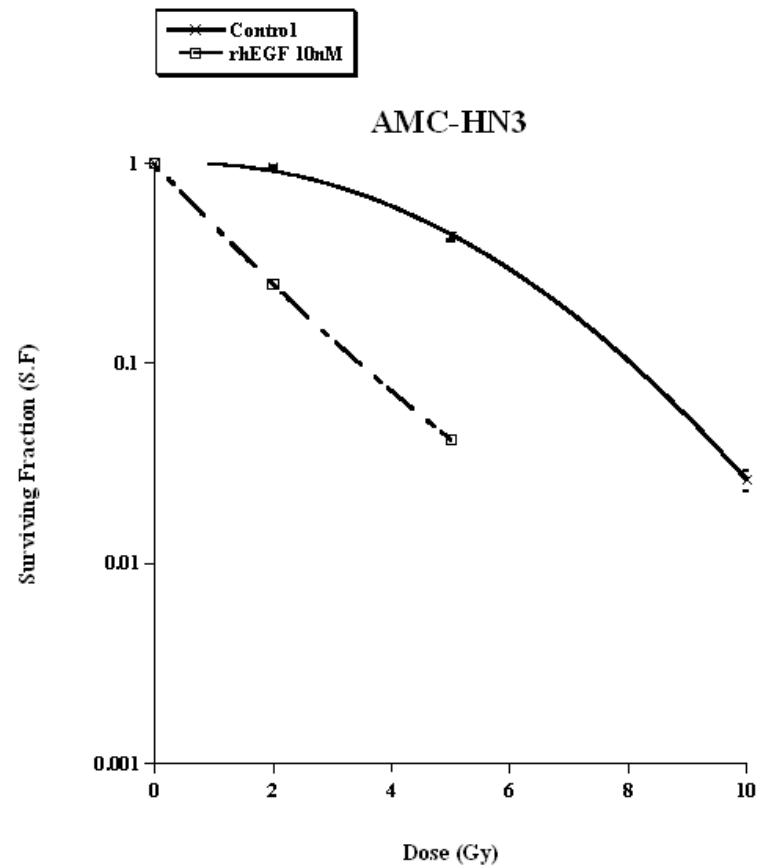

c

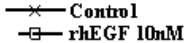

$\rightarrow$ rhEGF $10 \mathrm{nM}$

EMT-6

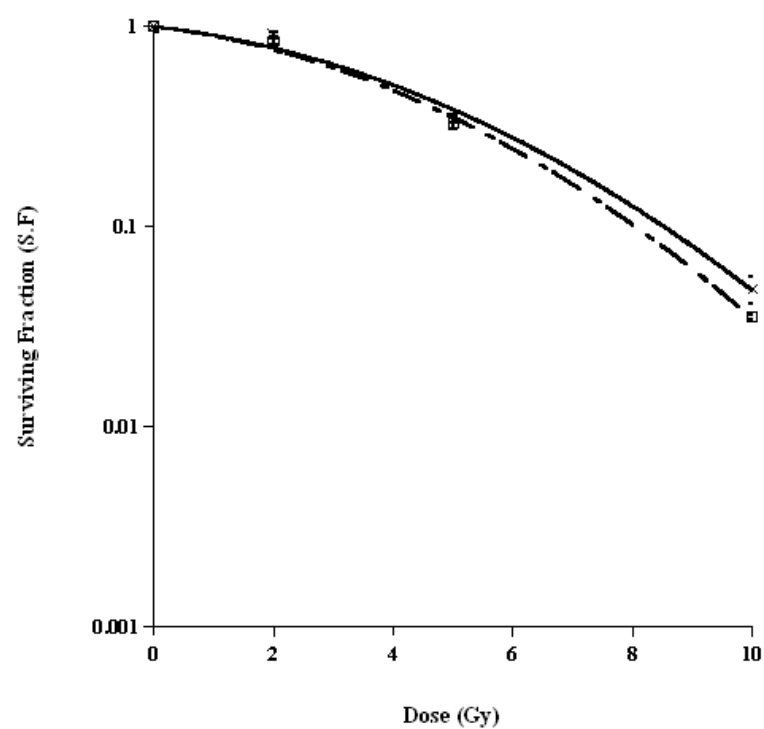

b

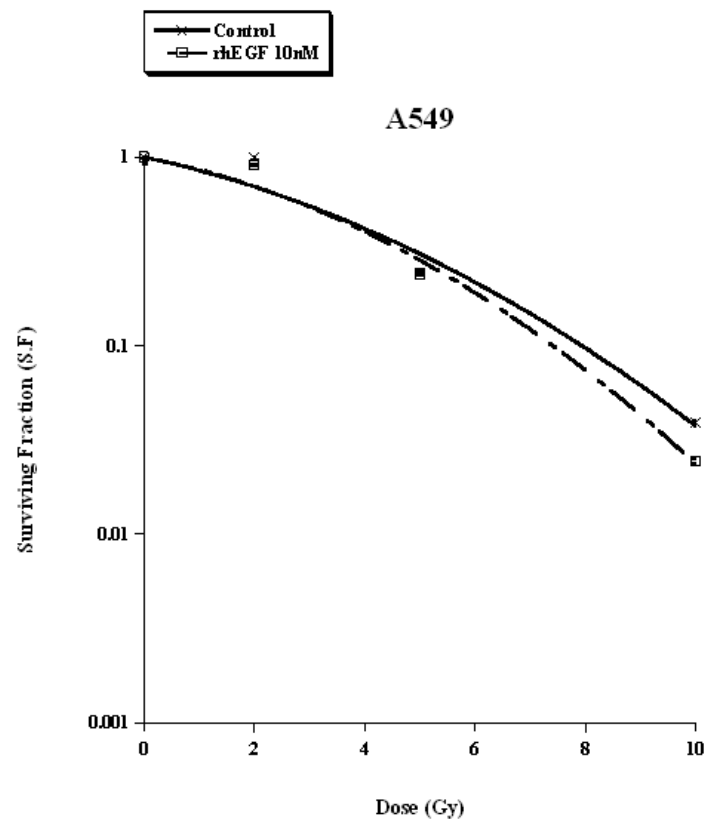

d

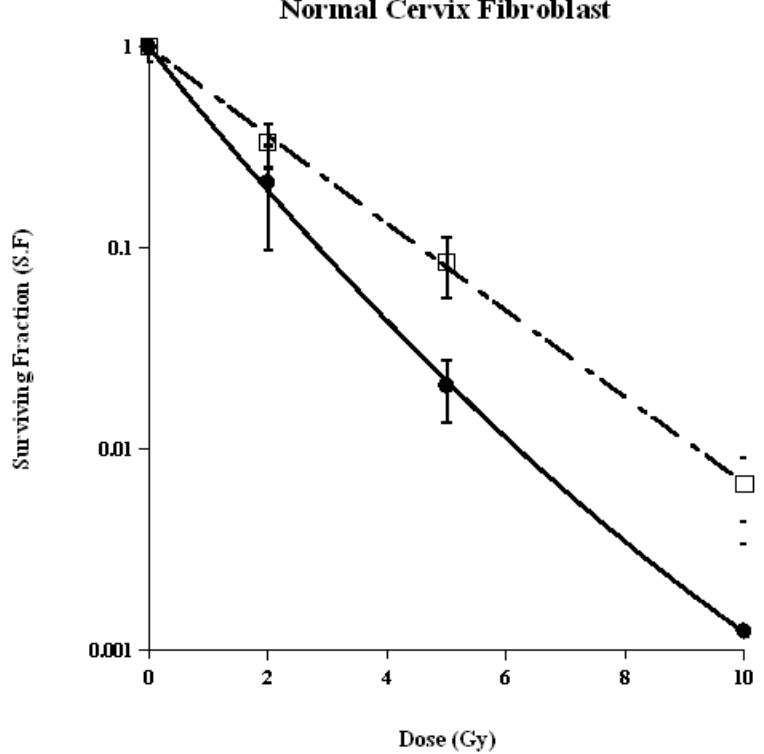

Fig. (3). Effects of rhEGF on cell killing of ionizing radiation.

(a) AMC-HN3, (b) A549, (c) EMT-6, (d) normal cervix fibroblast.

Cells were simultaneously irradiated and treated with rhEGF (10nM). After 24 hours, the medium was removed, and cells were incubated in drug-free media for 10 days to form colonies. rhEGF radiosensitized AMC-HN3 cells, but protected normal fibroblasts from the killing effect of radiation. 


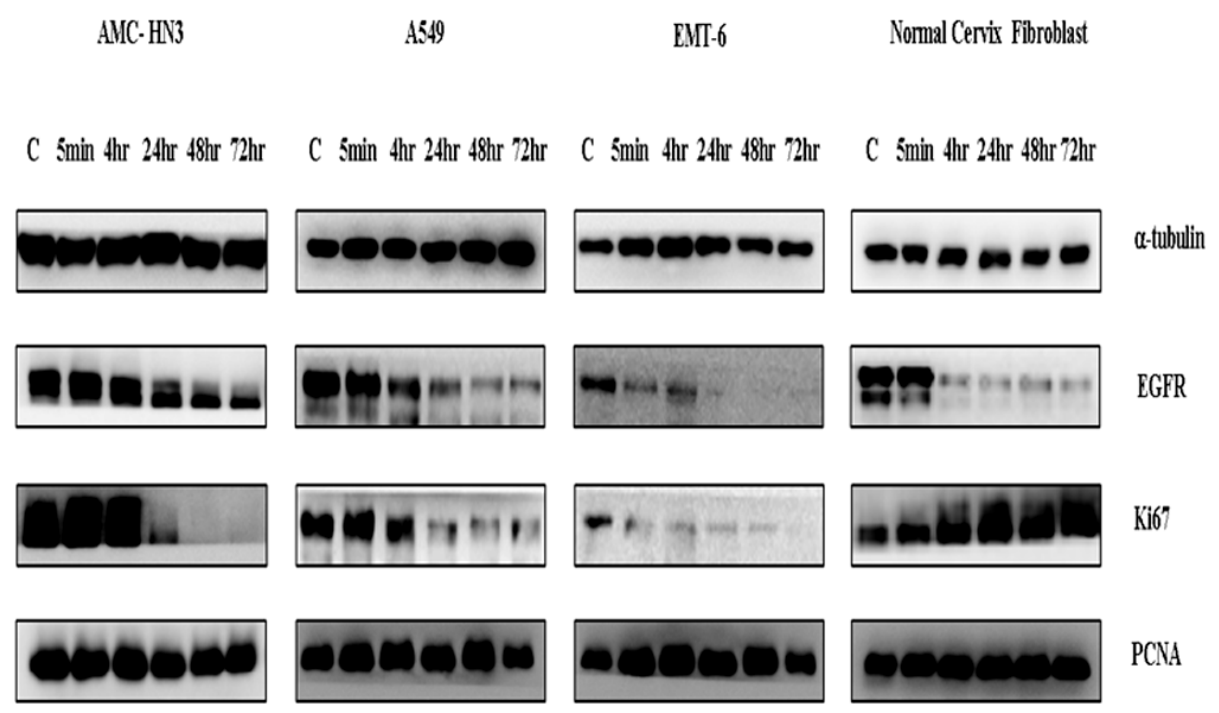

Fig. (4). rhEGF-induced changes in expression of EGFR, Ki67, and PCNA with respect to time.

The cells were incubated for 18-24 hours in serum-free media (0.5\% FBS) and treated with rhEGF (10nM) for 5 min, $4,24,48$, or 72 hours. Ki67 significantly decreased in cancer cell lines and increased in the normal fibroblasts.

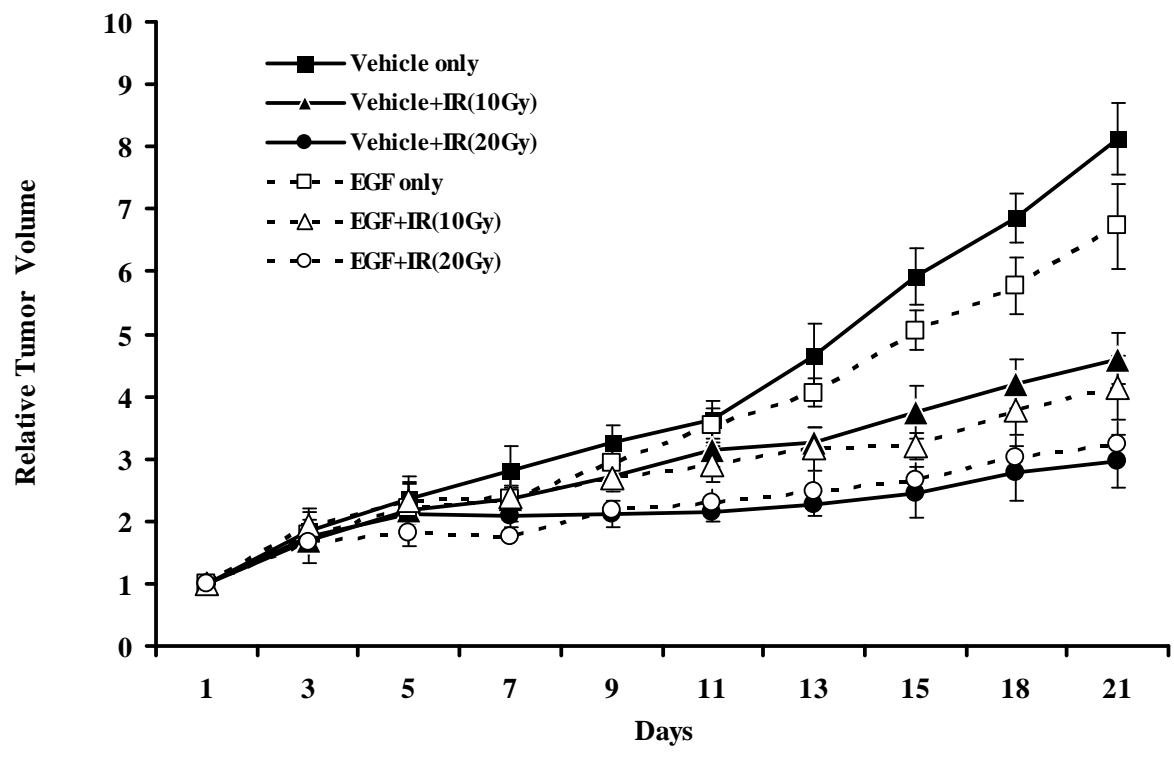

Fig. (5). Effects of rhEGF on tumor growth delay of ionizing radiation in Balb/c mice implanted with EMT-6 cells.

Each group was irradiated (if indicated) and then treated as indicated for 7 consecutive days, three times a day, following the irradiation. Vehicle only $=$ vehicle $(100 \mu \mathrm{l})$ without irradiation; Vehicle $+\mathrm{IR}(10 \mathrm{~Gy})=$ vehicle $(100 \mu \mathrm{l})$ with $10 \mathrm{~Gy}$; Vehicle+IR $(20 \mathrm{~Gy})=$ vehicle $(100 \mu \mathrm{l})$ with $20 \mathrm{~Gy} ; \mathrm{EGF}$ only = EGF $(1.0 \mathrm{mg} / \mathrm{kg})$ without irradiation; EGF+IR $(10 \mathrm{~Gy})=\mathrm{EGF}(1.0 \mathrm{mg} / \mathrm{kg})$ with $10 \mathrm{~Gy} ; \mathrm{EGF}+\mathrm{IR}(20 \mathrm{~Gy})=\mathrm{EGF}(1.0 \mathrm{mg} / \mathrm{kg})$ with $20 \mathrm{~Gy}$. The data are means $\pm \mathrm{SD}$ of three independent experiments. rhEGF, whether given alone or combined with radiation, did not stimulate tumor growth.

\section{DISCUSSION}

In this study, rhEGF enhanced the proliferation of normal fibroblasts, and inhibited the cell killing effect of radiation in this cell line. In contrast, AMC-HN3 cells showed significantly increased cell death upon rhEGF treatment, although there was no significant effect on A549 and EMT-6 cells lines. In the animal tumor model using EMT- 6 cells, rhEGF treatment did not inhibit the cell killing effect of radiation.

In addition, we showed rhEGF increased the expression of $\mathrm{Ki} 67$, which is a $359-\mathrm{kD}$ nuclear protein expressed by proliferating cells in all phases of the active cell cycle. On the other hand, PCNA showed relatively little change in its expression compared to Ki67. PCNA is a $36-\mathrm{kD}$ non-histone nuclear protein that plays a fundamental role in initiating cell proliferation, and it is also a marker for cells in early $\mathrm{G} 1$ or $\mathrm{S}$ phases of the cell cycle. The lack of an effect on PCNA expression suggests that rhEGF might affect cells during G2 or $M$ phases of the cell cycle. Still, the mechanisms of the differential effect of rhEGF on various cancer cell lines are unknown. In the previous work, high concentrations of EGF (nanomolar level) inhibited growth and promoted apoptosis of the human epidermoid carcinoma cell line A431 [19,20]. The A431 cells, like AMC-HN3 cells, also express high lev- 
els of EGFR. However, the interaction among EGF, EGFR, and radiation is a complex issue that needs thorough approach, and this issue is beyond the scope of our study. Further studies are needed to confirm the efficacy of rhEGF in a wider variety of cancer cell lines as well as to elucidate the mechanisms of such observation.

The most important finding of the present study is that rhEGF treatment did not inhibit the cell killing effect of ionizing radiation on cancer cell lines, both in vitro and in vivo. As mentioned earlier, rhEGF was already shown to be effective for the recovery of radiation-induced mucosal damage in the animal models $[9,10]$. Taken together, our study may support the hypothesis that rhEGF can be used as a safe and effective radioprotector.

However, there are several concerns that should to be clarified for the clinical application of rhEGF at the present time. First, our in vivo model was based on the murine mammary tumor with relatively low expression of EGFR. Although the higher expression level of EGFR was associated with increased cell death and even radiosensitization upon rhEGF treatment, it is not certain whether similar observation would be repeated in the in vivo model using human cancer cell lines with high expression of EGFR. Second, the fractionation scheme utilized in the current study is different from the conventional fractionation in the clinical setting. Lastly, $10 \mathrm{nM}$ dose of rhEGF was based on the study conducted by Gulli et al. [21], but it is still unknown whether this is the optimal concentration and whether the doseresponse relationship exist.

In conclusion, results of our study demonstrated that rhEGF effectively stimulated proliferation and radiation recovery in normal fibroblasts without promoting the growth of tumor cells. Therefore, it may be clinically valuable in preventing and/or treating radiation-induced tissue injuries and it may also potentially increase the therapeutic index of radiotherapy.

\section{ACKNOWLEDGEMENTS}

This work was supported by grant No. 0620270 from the National R\&D Program for Cancer Control, Ministry of Health Family \& Welfare, Republic of Korea, and grant No. R01-2008-000-20581-0 from the Korea Science and Engineering Foundation grant funded by the Korea government (MEST).

\section{REFERENCES}

[1] de la Torre A, Reguiero CA, Valcárcel FJ. Granulocytemacrophage colony-stimulating factor mouthwashes improve radiation induced mucositis in AIDS patients. Radiother Oncol 1997; 43: 229-30.

[2] Nicolatou O, Sotiropoulou-Lontou A, Skarlatos J, Kyprianou K, Kolitsi G, Dardoufas K. A pilot study of the effect of granulocytemacrophage colony-stimulating factor on oral mucositis in head and neck cancer patients during X-radiation therapy: a preliminary report. Int J Radiat Oncol Biol Phys 1998; 42: 551-6.
[3] Schneider SB, Nishimura RD, Zimmerman RP, et al. Filgrastim (rmetHuG-CSF) and its potential use in the reduction of radiationinduced oropharyngeal mucositis: an interim look at a randomized, double-blind, placebo-controlled trial. Cytokines Cell Mol Ther 1999; 5: 175-80.

[4] Makkonen TA, Minn H, Jekunen A, Vilja P, Tuominen J, Joensuu H. Granulocyte macrophage-colony stimulating factor (GM-CSF) and sucralfate in prevention of radiation-induced mucositis: a prospective randomized study. Int J Radiat Oncol Biol Phys 2000; 46: 525-34.

[5] Sonis ST, Peterson RL, Edwards LJ, et al. Defining mechanisms of action of interleukin-11 on the progression of radiation-induced oral mucositis in hamsters. Oral Oncol 2000; 36: 373-81.

[6] Saarilahti K, Kajanti M, Joensuu T, Kouri M, Joensuu H. Comparison of granulocyte-macrophage colony-stimulating factor and sucralfate mouthwashes in the prevention of radiation-induced mucositis: a double-blind prospective randomized phase III study. Int J Radiat Oncol Biol Phys 2002; 54: 479-85.

[7] Ryu JK, Swann S, LeVeque F, et al. The impact of concurrent granulocyte macrophage-colony stimulating factor on radiationinduced mucositis in head and neck cancer patients: a double-blind placebo-controlled prospective phase III study by Radiation Therapy Oncology Group 9901. Int J Radiat Oncol Biol Phys 2007; 67: 643-50.

[8] Finch PW, Rubin JS. Keratinocyte growth factor expression and activity in cancer: implications for use in patients with solid tumors. J Natl Cancer Inst 2006; 98: 812-24.

[9] Lee S, Jung KI, Kim YW, et al. Effect of epidermal growth factor against radiotherapy-induced oral mucositis in rats. Int $\mathrm{J}$ Radiat Oncol Biol Phys 2007; 67: 1172-8.

[10] Lee KK, Jo HJ, Hong JP, et al. Recombinant human epidermal growth factor accelerated recovery of mouse small intestinal mucosa after radiation damage. Int J Radiat Oncol Biol Phys 2008; 71: 1230-5.

[11] Servold SA. Growth factor impact on wound healing. Clin Pediatr Med Surg 1991; 8: 937-53.

[12] Weaver LT, Gonnella PA, Israel EJ, Walker WA. Uptake and transport of epidermal growth factor by the small intestinal epithelium of the fetal rat. Gastroenterology 1990; 98: 828-37.

[13] Cohen S. The epidermal growth factor (EGF). Cancer 1983; 51: 178-91.

[14] Steidler NE, Reade PC. Histomorphological effects of epidermal growth factor on skin and oral mucosa in neonatal mice. Arch Oral Biol 1980; 25: 37-43.

[15] Epstein JB, Gorsky M, Guglietta A, Le N, Sonis ST. The correlation between epidermal growth factor levels in saliva and the severity of oral mucositis during oropharyngeal radiation therapy. Cancer 2000; 89: 2258-65.

[16] Carpenter G, Cohen S. Epidermal growth factor. J Biol Chem 1990; 265: 7709-12.

[17] Hille A, Rave-Frank M, Pradier O, et al. Effect of keratinocyte growth factor on the proliferation, clonogenic capacity and colony size of human epithelial tumour cells in vitro. Int J Radiat Biol 2003; 79: 119-28.

[18] Slonina D, Hoinkis C, Dorr W. Effect of keratinocyte growth factor on radiation survival and colony size of human epidermal keratinocytes in vitro. Radiat Res 2001; 156: 761-6.

[19] Gill GN, Lazar CS. Increased phosphotyrosine content and inhibition of proliferation in EGF-treated A431 cells. Nature 1981; 293: 305-7.

[20] Pavel SG, Valery VZ, Andrey VK, Viktoria ND, Nikolay NN. EGF-induced apoptosis in A431 cells is dependent on STAT1, but not on STAT3. Eur J Cell Biol 2007; 86: 591-603.

[21] Gulli LF, Palmer KC, Chen YQ, Reddy KB. Epidermal growth factor-induced apoptosis in A431 cells can be reversed by reducing the tyrosine kinase activity. Cell Growth Differ 1996; 7: 173-8. 